\title{
STUDI PEMBERIAN MINUMAN REMPAH JAHE MERAH ( Zingiber Officinale VAR Rubrum Rhizoma) DAN KUNYIT (Curcuma Domestica VAL) TERHADAP PENURUNAN SKALA NYERI DISMEORE
}

\author{
Nur Awaliah ${ }^{1}$, Agung Rahmadani ${ }^{1}$, Dewi Rahmawati ${ }^{2}$, Jaka Fadraersada ${ }^{1,2}$ \\ ${ }^{1}$ Laboratorium Penelitian dan Pengembangan Kefarmasian "Farmaka Tropis", \\ Fakultas Farmasi, Universitas Mulawarman, Samarinda, Indonesia \\ ${ }^{2}$ Kelompok Bidang Ilmu Farmasi Klinik dan Komunitas, Fakultas Farmasi, \\ Universitas Mulawarman, Samarinda, Indonesia \\ *Email: NurAwaliaaah@gmail.com
}

\begin{abstract}
Red ginger and turmeric drinks contains active compounds of gingerol and curcumin which is thought to have a function as analgesic, antipyretic, and anti-inflammatory and can be used as a pain reliever during dysmenorrhea. The purpose of this reseach is to discover the characteristics and effectiveness of these drinks to 30 dysmenorrhea female students at Mulawarman University Faculty of Pharmacy. This research use quasy experimental with accidental sampling as sampling technique. The procedure in this study used measurements of the initial pain scale (Pre-Test) and the final pain scale (Post-Test). The results of characteristic data showed the highest percentage of female students who had regular menstrual cycles of 27 people (81\%) with a duration of pain> 1 hour 20 people (66.67\%), experience abdominal pain symptoms were 14 people (46.6\%), disturbed lectures were, 20 people (66.67\%), and handling the pain with resting were 18 people (60\%). The results of the analysis using the one way ANOVA statistical test obtained in the administration of red ginger $p$ value $=0,00017<0,05$, while in turmeric $p$ value $=$ 0,000322 . The concluded, there is an influence of red and turmeric ginger spices on the scale of dysmenorrhea pain reduction.
\end{abstract}

Keyword: Red Ginger drink, Turmeric drink, dysmenorrhea

\begin{abstract}
ABSTRAK
Minuman rempah jahe merah dan kunyit mengandung senyawa aktif gingerol dan kurkumin yang diduga memiliki fungsi sebagai analgetika, antipiretika, dan antiinflamasi dan dapat digunakan sebagai pengurang rasa nyeri pada saat dismenore.Penelitian ini bertujuan untuk melihat karakteristik, pengaruh pemberian minuman rempah terhadap 30 mahasiswi dismenore di Fakultas Farmasi Universitas Mulawarman. Penelitian ini menggunakan quasy eksperimental dengan teknik sampling accidental sampling. Prosedur dalam penelitian ini menggunakan pengukuran skala nyeri awal (Pre-Test) dan skala nyeri akhir (Post-Test). Hasil data karakteristik didapatkan persentase tertinggi pada mahasiswi yang memiliki siklus menstruasi teratur 27 orang $(81 \%)$ dengan lama nyeri $>1$ jam 20 orang $(66,67 \%)$, gejala yang dialami nyeri perut 14 orang $(46,6 \%)$, menganggu aktivitas
\end{abstract}


perkuliahan 20 orang $(66,67 \%)$, dan menangani rasa sakit dengan istirahat 8 orang $(60 \%)$. Hasil analisis menggunakan uji statistik one way anova didapatkan pada pemberian jahe merah nilai $p$ value $=0,00017<0,05$, sedangkan pada kunyit nilai $\mathrm{p}$ value $=0,000322$. Hal ini menunjukan bahwa terdapat pengaruh minuman rempah jahe merah dan kunyit terhadap penurunan skala nyeri dismenore.

Kata Kunci : Dismenore, Minuman Rempah, Jahe Merah, Kunyit

DOI: https://doi.org/10.25026/mpc.v8i1.330

\section{PENDAHULUAN}

Perubahan

perkembangan

biologis pada remaja yaitu di mulainya haid (menstruasi) ${ }^{[1]}$.Secara periodik setiap bulan wanita normal akan mengalami peristiwa produksi, yaitu menstruasi, meluruhnya jaringan endometrium karena tidak adanya sel telur yang matang dan dibuahi oleh sperma. Kebanyakan wanita mengalami masalah menstruasi diantaranya adalah nyeri haid.

Nyeri haid (Dismenore) ialah ketidakseimbangan hormon progesteron dalam darah sehingga menimbulkan rasa nyeri. Wanita yang mengalami dismenore memproduksi prostaglandin 10 kali lebih banyak daripada wanita yang tidak dismenore. Prostaglandin menyebabkan meningkatnya kontraksi di uterus sehingga menimbulkan rasa nyeri pada saat menstruasi ${ }^{[2]}$

Dismenore menyebabkan wanita tidak mampu melakukan kegiatan seharihari sehingga apabila masalah tidak diatasi akan sangat merugikan ${ }^{[3]}$ Angka kejadian nyeri menstruasi didunia sangat besar. Tingkat prevalensi bervariasi diseluruh dunia, di Cina angka persentasenya kira-kira 44\%, di Singapura 51\%, di Meksiko 52-64\%, di Amerika Serikat 60-80\%, di Swedia 73\%, di Australia Barat 80\%, di Britania 4595\% (Yeh, 2007) sedangkan di Indonesia angka persentasenya sekitar $54,89 \%{ }^{[4]}$

Untuk mengatasi nyeri menstruasi (dismenore) dapat dilakukan dengan terapi farmakologi dan non farmakologi. Terapi farmakologi seperti pemberian obat-obat analgetik, dan obat NSAID. Namun sifat obat-obatan tersebut hanya menghilangkan rasa nyeri, maka penderita akan mengalami ketergantungan obat dalam jangka panjang. Apabila dikonsumsi terus menerus dapat menimbulkan efek samping yang negatif bagi kesehatan seperti gangguan pada lambung, anemia, dan dampak mental psikologis yang membuat pengkonsumsinya tersugesti dan tidak bisa melepaskan diri dari obatobatan. Sehingga mereka meras bahwa untuk tidak nyeri menstruasi maka harus minum obat ${ }^{[5]}$ Sedangkan untuk terapi non farmakologi dapat dilakukan dengan terapi suplemen, terapi akupuntur, terapi tingkah laku, aroma terapi dan terapi herbal seperti kunyit asam dan jahe ${ }^{[6][7]}$

Penelitian terdahulu sudah banyak ditemukan bahwa jamu dapat digunakan untuk mengatasi nyeri haid. Suatu jamu dikatakan aman untuk dikonsumsi jika turun temurun melewati tiga generasi dan terbukti aman, atau telah diuji toksisitasnya serta tercatat di buku resmi yang diterbitkan lembaga resmi pemerintah atau dunia, perguruan tinggi dan jurnal ${ }^{[8]}$. Produk herbal atau jamu atau fitofarmaka saat ini sedang menjadi alternative utama bagi remaja putri yang ingin mengurangi rasa nyeri dismenore tanpa mendapat efek samping [9], salah satunya adalah dengan minum jahe merah dan kunyit. 
Kandungan kimia gingerol pada jahe merah yang dapat bersifat sebagai analgetik, antipiretik. Gingerol sendiri bekerja dengan memblokir kerja prostaglandin sehingga dapat menurunkan nyeri pada saat menstruasi $^{[10]}$. Kandungan kimia kurkumin pada kunyit berfungsi sebagai penghambat siklooksigenase sehingga dapat mengurangi terjadinya inflamasi pada saat kontraksi uterus ${ }^{[11]}$

Sehingga perlunya dilakukan pemberian minuman rempah jahe merah dan kunyit ini untuk mengatasi nyeri dismenore pada mahasiwi Fakultas Farmasi Universitas Mulawarman untuk melihat apakah terdapat pengaruh penurunan nyeri yang diberikan setelah mongkonsumsi minuman rempah jahe merah dan kunyit.

\section{METODE}

Metode penelitian yan digunakan quasi eksperimen. Rancangan peneltian ini adalah pre-posttest control group design. Rancangan adalah pre-posttest control group design dilakukan dengan menilai sebelum dan setelah perlakuan pada kelompok kontrol dan intervensi. Teknik pengambilan sampel dalam penelitian ini adalah dengan menggunakan assidental sampling. Dalam pengambilan sampel didasarkan pada kriteria inklusi antara lain:

1. Mahasiswi yang mengalami dismenore

2. Mahasiswi berusia 18-23 tahun

3. Mahasiswi yang bersedia tidak menggunakan terapi farmakologi dan non farmakologi

4. Mahasiswi yang bersedia menjadiresponden (bersedia minum minuman rempah jahe merah dan kunyit)

Mahasiswi penelitian ialah mahasiswi Fakultas Farmasi Universitas Mulawarman yang mengalami dismenore. Tingkat nyeri sebelum dan setelah akan diukur menggunakan Numeric Rating Scale. Kelompok perlakuan diukur skala nyerinya sebelum dan setelah diberikan serbuk jahe merah dan kunyit dilarutkan dalam $150 \mathrm{cc}$ air hangat pada hari pertama nyeri dismenore.. Analisa data menggunakan SPSS One Way Annova.

\section{HASIL DAN PEMBAHASAN}

Tabel 1. Data Karakteristik

\begin{tabular}{llcc}
\hline Kategori & Karakteristik & $\begin{array}{c}\text { Jumlah } \\
\text { responden }\end{array}$ & Persentase \\
\hline Siklus menstruasi & Teratur & 19 & $95 \%$ \\
& Tidak Teratur & 1 & $6 \%$ \\
Lama nyeri & $>1$ jam & 14 & $70 \%$ \\
& <1 jam & 6 & $30 \%$ \\
Gejala menstruasi & Nyeri Perut & 13 & $65 \%$ \\
& Pusing & 3 & $15 \%$ \\
& Mual & 2 & $10 \%$ \\
Nyeri menganggu & Mules & 2 & $10 \%$ \\
kegiatan & Ya & 11 & $55 \%$ \\
Penanganan & Tidak & 9 & $45 \%$ \\
& Istirahat & 14 & $70 \%$ \\
& Minuman Herbal & 4 & $20 \%$ \\
& Minyak & 1 & $5 \%$ \\
& Bergerak & 1 & $5 \%$ \\
\hline
\end{tabular}

Berdasarkan tabel 1 dari 20 responden sebagian besar responden menstruasinya teratur yaitu sebanyak 19 responden (95\%) dan 1 responden $(5 \%)$ dengan menstruasi yang tidak teratur. Siklus menstruasi normal pada wanita berbeda-beda sekitar 25-35 hari. Siklus menstruasi dihitung dari hari perdarahan bermula yang disebut sebagai hari pertama hingga satu hari sebelum perdarahan menstruasi pada bulan berikutnya yang disebut dengan hari terakhir Namun, terdapat beberapa wanita yang tidak memiliki siklus haid teratur dan hal ini bisa terjadi karena adanya masalah kesuburan ${ }^{[12]}$

Gangguan ketidakteraturan pada wanita juga bisa disebabkan karena polimenore (mesntruasi kurang dari 21 hari), Oligomenorea (menstruasi lebih dari 35 hari), dan Amenorea (tidak adanya menstruasi minimal 3 bulan berturut-turut. 
Menurut pendapat peneliti, penelitian tersebut menunjukkan bahwa remaja yang siklus haidnya normal banyak yang mengalami nyeri haid. Jadi siklus haid normal maupun tidak normal dapat mengalami nyeri haid.

Berdasarkan tabel 1 dari 20 responden lama nyeri menstruasi >1jam pada responden sebanyak 14 orang $(70 \%)$ dan lama nyeri <1jam pada responden sebanyak 6 orang $(30 \%)$. Lama menstruasi rata-rata perempuan antara 3-8 hari, jika lebih dari normal, menimbulkan adanya kontraksi uterus, bila menstruasi terjadi lebih lama mengakibatkan uterus lebih sering berkontraksi dan semakin banyak prostaglandin yang dikeluarkan. Produksi prostaglandin yang berlebihan menimbulkan rasa nyeri, sedangkan kontraksi uterus yang terus menerus menyebabkan suplay darah ke uterus terhenti dan terjadi disminore.

Sementara secara fisiologis lebih kepada terjadinya kontraksi otot uterus yang berlebihan atau dapat dikatakan mereka sangat sensitif terhadap hormon ini akibat endometrium dalam fase sekresi memproduksi hormon prostaglandin. Prostagladin terbentuk dari asam lemak tak jenuh yang disintesis oleh deluruh sel yanga ada dalam tubuh. Hal ini menyebabkan kontraksi otot polos yang akhirnya menimbulkan rasa nyeri.

Nyeri merupakan perasaan yang tidak menyenangkan dan bersifat subyetif yang tidak dapat dibagi dengan orang lain, meskipun setiap individu mendapatkan stimulus yang sama. Stimulus dari adanya kontraksi uterus dan ischemia jaringan endometrium karena sekresi prostaglandin yang berlebihan, tetapi reaksi yang ditunjukan setiap orang berbeda- beda ${ }^{[13]}$.

Nyeri yang dirasakan responden tetap karena nyeri dipengaruhi oleh beberapa faktor, diantaranya pengalaman masa lalu, ansietas, budaya, usia, keletihan, perhatian dan makna nyeri . Responden yang mengalami nyeri berkepanjangan akan lebih toleras terhadap rasa nyeri dibandingkan dengan responden yang tidak mengalami nyeri, sehingga walaupun dilakukan perlakuan tertentu akan merasakan nyeri yang tetap. Kontraksi uterus dan ischemia jaringan endometrium karena sekresi prostaglandin yang berlebihan, tetapi reaksi yang ditunjukkan setiap orang berbeda ${ }^{[14]}$ Nyeri yang dirasakan oleh responden tetap karena nyeri dipengaruhi oleh beberapa faktor, diantaranya pengalaman masa lalu, ansietas, budaya, usia, keletihan, perhatian dan makna nyeri . Responden yang mengalami nyeri berkepanjangan akan lebih toleras terhadap rasa nyeri dibandingkan dengan responden yang tidak mengalami nyeri, sehingga walaupun dilakukan perlakuan tertentu akan merasakan nyeri yang tetap.

Berdasarkaan tabel 1, gejala menstruasi pada 20 responden antara lain nyeri perut sebanyak 13 orang $(65 \%)$, pusing 3 orang $(15 \%)$, mual 2 orang $(10 \%)$, dan mules 2 orang (10\%).

Beberapa gejala saat dismenore seperti nyeri pada perut bagian bawah, yang bisa menjalar ke punggung bagian bawah dan tungkai, nyeri dirasakan sebagai kram yang hilang-timbul atau sebagai nyeri tumpul yang terus menerus, terkadang disertai rasa mual, muntah, pusing atau pening [15]. Endometrium dalam fase sekresi memproduksi prostaglandin F2 sehingga menyebabkan kontraksi otot-otot polos. Jika kadar prostaglandin yang belebihan memasuki peredaran darah, maka selain dismenore dapat juga dijumpai efek lainnya seperti: nausea, muntah, diarea, flushing ${ }^{[16]}$.

Berdasarkan tabel 1 nyeri dirasakan responden yang mengalami dismenore dan menganggu perkuliahan sebanyak 11 orang (55\%) sedangkan yang mengalami dismenore dan tidak menganggu kgiatan perkuliahan sebanyak 9 orang $(45 \%)$.

Keluhan yang muncul pada dismenore bisa menghambat aktivitas sehari hari dan bisa mengganggu 
konsentrasi belajar atau bekerja. Pada umumnya dismenore ini tidak membahayakan namun dapat menganggu penderitanya.

Gangguan menstruasi dapat disebabkan karena adanya kelainan biologik (organik atau disfungsional) gangguan psikologik, (seperti keadaan stress atau keadaan emosi) atau gabungan biologik dan psikologik.

Berdasarkan tabel 1, penanganan yang dilakukan pada 20 responden untuk mengurangi rasa nyeri ialah istirahat 14 orang $(70 \%)$, minuman herbal 4 orang (20\%), minyak kayu putih 1 orang $(5 \%)$, dan bergerak 1 orang $(3,3 \%)$

Segolongan perempuan yang mengalami dismenorea primer mengatasi serta menyembuhkan nyeri haid tersebut dengan mengkonsumsi obat-obatan secara berkala. Namun sifat obat-obatan tersebut hanya menghilangkan rasa nyeri, maka penderita akan mengalami ketergantungan obat dalam jangka panjang. Apabila dikonsumsi terus menerus akan menimbulkan dampak negatif bagi kesehatan. Penggunaan obat farmakologis menimbulkan efek samping seperti gangguan pada lambung, anemia, dan yang lebih parah adalah dampak mental psikologis yang membuat penderitanya tersugesti dan tidak bisa melepaskan diri dari obat-obatan. Mereka merasa bahwa untuk tidak mengalami nyeri haid maka harus minum obat [1] Selain dengan obat-obatan, rasa nyeri juga bisa dikurangi dengan istirahat yang cukup, olahraga yang teratur, pemijatan dan kompres hangat. Selain itu nyeri haid juga bisa diobati dengan menggunakan tumbuhan herbal antara lain tapak liman, temu putih, kunyit dan sidaguri ${ }^{[18]}$

Banyak hal yang dilakukan untuk mengurangi rasa nyeri pada dismenorea, misalnya mengkonsumsi obat-obatan analgetik, olahraga teratur, dan mengkonsumsi produk-produk herbal yang telah dipercaya khasiatnya ${ }^{[19]}$

Kejadian dismenore akan meningkat dengan kurangnya olaharaga, sehingga ketika terjadi dismenore, oksigen tidak dapat tersalurkan ke pembuluh - pembuluh darah di organ reproduksi yang saat itu terjadi vasokonstriksi sehingga menyebabkan timbulnya rasa nyeri tetapi bila seseorang teratur melakukan olahraga, maka dia dapat menyediakan oksigen hampir 2 kali lipat per menit sehingga oksigen tersampaikan ke pembuluh darah yang mengalami vasokonstriksi. Hal ini akan menyebabkan terjadinya penurunan dismenore $^{[20]}$

Sebagian besar remaja tidak menangani dismenore yang mereka alami dan ada sebagian remaja melakukan penanganan yang terbatas seperti hanya mengoleskan minyak kayu putih atau balsem pada daerah yang nyeri, tiduran, dan minum obat pengurang rasa sakit yang beredar dipasaran tanpa konsultasi dengan dokter. Sepertinya dismenorea dianggap hal yang wajar dan seringkali dianggap remeh, sehingga dapat mengakibatkan keterlambatan diagnosis endometriosis dan radang panggul kronik karena dismenorea dapat merupakan gejala klinis endometrosis atau radang panggu kronik $^{[21]}$

\section{Analisis perbedaan minuman rempah jahe merah dan kunyit mefenamat terhadap penurunan skala nyeri dismenorea}

\begin{tabular}{llllll} 
Jahe Merah & \multicolumn{5}{l}{} \\
\hline & $\begin{array}{l}\text { Sum of } \\
\text { Squares }\end{array}$ & $\begin{array}{l}\text { Mean } \\
\text { Square }\end{array}$ & Sig \\
\hline Between Groups & 8.450 & 1 & 8.450 & 33.800 & 0.00017 \\
Within Groups & 4.500 & 18 & .250 & & \\
Total & 12.950 & 19 & & & \\
\hline
\end{tabular}

\begin{tabular}{llllll} 
Kunyit & \multicolumn{3}{l}{} & & \\
& $\begin{array}{l}\text { Sum of } \\
\text { Squares }\end{array}$ & & $\begin{array}{l}\text { Mean } \\
\text { Square }\end{array}$ & F & Sig \\
\hline Between Groups & 7.200 & 1 & 7.200 & 19.636 & 0,000322 \\
Within Groups & 6.600 & 18 & .367 & & \\
Total & 13.800 & 19 & & & \\
\hline
\end{tabular}


Untuk mengetahui pengaruh penurunan pemberian minuman rempah jahe merah, kunyit dalam mengurangi nyeri dismenorhea primer, maka dilakukan menggunakan one-way anova. Hasil analisis disajikan dalam tabel di atas hasil menunjukkan bahwa terdapat pernurunan pengurangan nyeri dismenorea pada responden yang mengkonsumsi minuman rempah jahe merah, minuman rempah kunyit $\mathrm{P}=$ $0,00017, \quad \mathrm{P}=0,000322$. Meskipun minuman rempah jahe merah dan kunyit samasama terbukti dapat mengurangi nyeri dismenorea namun disimpulkan bahwa minuman rempah jahe merah lebih efektif dibanding minuman rempah kunyit dalam mengurangi nyeri dismenore.

Efektifitas rimpang jahe dan kunyit dalam mengurangi nyeri dismenorea primer sudah terbukti secara ilmiah melalui suatu riset, baik dalam bentuk sediaan simplisia maupun ekstraksi. Salah satu penelitian tentang efektifitas penggunaan rimpang jahe dalam mengurangi nyeri dismenore primer pada remaja adalah penelitian yang dilakukan oleh Rahmana, et.al (2014) dengan judul "Effect of Zingiber officinale R. rhizomes (Ginger) on Pain Relief in Primary Dysmenorrhea", menyatakan bahwa pemberian terapi ekstrak jahe terbukti efektif mengurangi nyeri dismenore primer pada remaja dengan hasil $\mathrm{P}$ kelompok perlakuan yang diberikan ekstrak jahe $(n=56)=0,015$, dan $P$ kelompok placebo $(n=46)=0,029$. Penelitian lain tentang efek klinis jahe dalam mengobati dismenore primer dilakukan oleh Kashefi, et.al (2014) yang berjudul "Comparison of the Effect of Ginger and Zinc Sulfate on Primary Dysmenorrhea", didapatkan hasil bahwa jahe (ekstrak) dan zinc sulfat memiliki efek positif yang sama dalam pengurangan nyeri dismenore primer pada wanita muda, dari total responden 150 yang dibagi menjadi tiga kelompok (jahe, zinc sulfat dan placebo), dengan nilai $\mathrm{p}=0,001<0,05$.

Pemberian kunyit dalam mengurangi nyeri dysmenorrhea sudah dikenal luas oleh masyarakat pada umumnya. Penelitian tentang penggunaan simplisia kunyit guna mengurangi nyeri haid pernah dilakukan oleh Anindita (2010), dengan judul "Pengaruh Kebiasaan Mengkonsumsi Minuman Kunyit Asam terhadap Keluhan Dismenorea Primer pada Remaja Putri di Kotamadya Surakarta", didapatkan hasil $\mathrm{X} 2$ hitung $=25,4524>\mathrm{X} 2$ tabel $(\alpha=0,05)$ $=3,841$. Dapat disimpulkan bahwa terdapat pengaruh kebiasaan mengkonsumsi minuman kunyit asam terhadap keluhan dismenorea primer pada remaja putri di Kotamadya Surakarta. Penelitian serupa juga pernah dilakukan oleh Suciani, et.al (2012) tentang "Efektivitas Pemberian Rebusan Kunyit Asam terhadap Penurunan Dysmenorrea", menjelaskan bahwa pemberian rebusan kunyit asam efektif menurunkan nyeri dysmenorrhea, dengan hasil uji statistic $\mathrm{P}=0,01<0,05$.

Jahe merah, dengan nama ilmiah Zingiber officinale Var merupakan rimpang yang mengandung gingerol dan shogaols. Kandungan gingerol pada jahe dapat menghambat enzim cyclooxygenase dan lipooxygenase dalam sintesis prostaglandin dan leukotriene. Zat anti radang pada jahe juga dapat menghambat sintesis prostaglandin. Hal ini merupakan mekanisme kunci dari efek gingerol dalam mengurangi rasa nyeri saat menstruasi (Gizana, Lindmark, dkk, 2005). Jahe dapat merangsang pelepasan hormon adrenalin dan memperlebar pembuluh darah, akibatnya darah mengalir lebih cepat dan lancar dan memperingan kerja jantung memompa darah, sehingga dapat mengurangi rasa sakit. Dapat dijelaskan lebih lanjut, bahwa inhibisi enzim siklooksigenase (COX-2) dapat mencegah kerusakan membran sel yang menghasilkan asam fosfolipase, asam fosfatase, dan ion 
kalsium guna terbentuknya asam arakidonat. Apabila pembentukan asam arakidonat dicegah, maka hasil metabolisme dari asam arakidonat berupa prostaglandin $\quad(\mathrm{PGF} 2 \alpha) \quad$ yang menyebabkan konstruksi artiole endometrium dan kontraksi myometrium yang menyebabkan terjadinya dismenore primer, dapat dicegah. Penyebab terjadinya rasa nyeri dismenorrea adalah karena pengaruh terjadinya respons inflamasi akibat siklus prostaglandin dan leukotrienes. Kedua agen ini diproduksi oleh kerja metabolisme asam arachidonic. Prostaglandin distimulasi oleh enzim cyclooxygenase, sedangkan leukotriens oleh enzim lipooxygenase. Sintesis prostaglandin (PGF2-alfa) di dalam uterus akan berakibat pada hipertonus dan vasokonstriksi pada myometrium yang dapat menimbulkan iskemia dan nyeri pada dismenorea primer. Leukotrien lebih berperan dalam hal peningkatan sensitivitas serabut saraf yang menyebabkan sensasi nyeri pada uterus.

\section{KESIMPULAN}

Didapatkan persentase tertinggi pada mahasiswi yang memiliki siklus menstruasi teratur 19 orang (95\%) dengan lama nyeri $>1$ ja 14 orang ( $70 \%$ ) , gejala yang dialami nyeri peru 13 orang (65\%), menganggu aktivitas perkuliahan 11 orang $(55 \%)$, dan menangani dengan istirahat 14 orang $(70 \%)$. Dan terdapat pengaruh minuman rempah jahe merah dan kunyit terhadap penurunan skala nyeri dismenore pada mahasiswi Fakulas Farmasi Universitas Mulawarman.

\section{DAFTAR PUSTAKA}

[1] Gilly, Adrews. 2009. Buku Ajar Kesehatan Reproduksi Wanita, Edisi 2. EGC : Jakarta.

[2] Ernawati. 2010. Terapi Relaksasi Terhadap Nyeri Dismenore Pada Mahasiswi Universitas Muhamadiyah Semarang. Jurnal Unimus vol 1 no 1.
[3] Rahmana P, Montazeri Ali, Huseini HF, Kianbakhi S, Nae M. 2012. Effect of Zingiber Officinale R.Rhizoma (ginger) on pain relief I Primary dysmenorrhea : a placebo randomized ria BMC. Complementary and Alternative Med. 12(92) : 1-7.

[4] Nazari, P. E. 2011. Hubungan Antara Body Image, Asupan Zat Gizi dengan Status Gizi dan Kejadian Dysmenorrhea Primer Anak Perempuan yang Mengalami Menarche pada Usia 12 Tahun. Tidak Dipublikasikan. Skripsi. Surabaya: Fakultas Kesehatan Masyarakat. Universitas Airlangga.

[5] Anurogo, D., Dkk. 2011. Cara Jitu Mengelola Nyeri Haid.Yogyakarta: C.V Andi Offset.

[6] Suciani, S.R., 2004. Efektivitas pemberian rebusan kunyit asam terhadap penurunan Dismenorea. pp.1-8

[7] Rigi, S.N. Shahindokht Navvabi Rigi, Fatihe kermansaravi, Ali Navidian, Leila Safabakhsh, Comparing the analgesic effect of heat patch containing iron chip and ibuprofen for primary dysmenorrhea: a randomized controlled trial. BMC Women's Health, 12(1), p.1. Available at: BMC Women's Health

[8] Tepy, Usia, 2010, Apakah Produk Herbal Yang Anda Konsumsl Aman, Bermutu Dan Bermanfaat . info POM volume XI, No.4, Badan POM RI.

[9] Kylenorton. 2010. Menstruation Disorders - Dysmenorrhea - How Chinese Herbs Can Help to Treat and Prevent Dysmenorrhea.

[10]Ozgoli. G., Goli, M. Moattar F. Comparison of effects of ginger, mefenamic acid, and ibuprofen on pain in women with primary dysmenorrhea.The Jurnal of alternative and complementary medicine; 2009. 
[11]Heinrich M., Barnes J. Gibbsions., dan Williamson E.M. 2010. Farmakognosi dan Fitoterapi Edisi 1. EGC : Jakarta

[12]Biohealth Indonesia, 2007. Siklus Menstruasi Wanita. From: http://www.BioHealthWorld.com

[13]Kozier , B 2004, Fundamentals of nursing concepts, process and practice, 7th Ed., Pearson Education Line, New Jersey.

[14]Kasdu, D. 2008. Solusi Problem Wanita Dewasa. Jakarta: Puspa Swara, Anggoru IKAPI.

[15] Kristina. 2010. Disminore primer. Jakarta: Balai Pustaka.

[16]Carrington \& Wilson, J.R. 1991. Obstretrics and Gynecology. Mosby year book. Edisi 9. St. Louis : MO.
[17] Anurogo,D. \& Wulandari, A. 2011. Cara Jitu Mengatasi Nyeri Haid. Yogyakarta: ANDI Yogyakarta.

[18]Leli, Rahmawati \& Atik. 2011. Pengaruh kunyit asam terhadap penanganan nyeri haid pada siswi kelas xi sma negeri $i$ sugihwaras. Diperoleh tanggal 2 Juli 2013.

[19] Smith R.P. 2003. Dysmenorrhea: Etiology, Diagnosis, and Therapy.

[20] Tjokronegoro. 2004. Buku Ajar Ilmu Penyakit Dalam Jilid I. Jakarta : Gaya Baru

[21]Braverman PK. Dysmenorrhea and premenstrual syndrome. Dalam: Neinstein LS, Gordon CM, Katzman DK, Rosen DS, Woods ER, penyunting. Adolescent health care a practical guide. Edisi ke-5. Philadelphia: Lippincott Williams and Wilkins; 2008 